\title{
PENINGKATAN KINERJA MEMBRAN ULTRAFILTRASI ALIRAN DEAD- END PADA PENYISIHAN BAHAN ORGANIK DALAM EFLUEN IPAL DOMESTIK DENGAN PRA-PERLAKUAN ADSORPSI
}

\author{
IMPROVEMENT OF DEAD-END FLOW ULTRAFILTRATED MEMBRANE PERFORMANCE IN \\ ORGANIC MATERIAL REMOVAL IN DOMESTIC WWTP EFLUEN WITH ADSORPTION PRE- \\ TREATMENT
}

\author{
Anisa Yuliani, Mahmud, Chairul Abdi \\ Teknik Lingkungan, Fakultas Teknik, Universitas Lambung Mangkurat \\ E-mail : anisayulianil6@yahoo.com
}

\begin{abstract}
ABSTRAK
Salah satu kendala yang membatasi kinerja membran ultrafiltrasi (UF) yaitu fouling membran. Keberadaan Bahan Organik (BO) merupakan salah satu penyebab utama terjadinya fouling membran pada air efluen IPAL Domestik. Oleh karena itu, perlu dilakukan pra-perlakuan adsorpsi karbon aktif untuk mengurangi fouling dan meningkatkan performa membran UF. Penelitian ini bertujuan untuk mengetahui proses pengolahan air efluen dengan kondisi terbaik pada proses hibrid adsorpsi dan Ultrafiltrasi (UF) selulosa asetat (SA), serta menganalisis terbentuknya fouling membran pada proses hibrid adsorpsi dan UF-SA. Karbon aktif yang digunakan pada rencana penelitian ini adalah Powdered Activated Carbon (PAC) dengan interval variasi dosis $25 \mathrm{mg} / \mathrm{L}$ pada rentang $25 \mathrm{mg} / \mathrm{L}-200 \mathrm{mg} / \mathrm{L}$ serta $\mathrm{pH} 4$. Metode yang digunakan pada proses pra-perlakuan adsorpsi menggunakan sistem batch dengan pengadukan adsorpsi 180 rpm selama 240 menit. Kemudian, dialirkan pada membran UF-SA menggunakan sistem aliran dead-end dengan variasi tekanan operasi 1-3 bar dengan interval 0,5 bar pada $\mathrm{pH} 4$ selama 120 menit. Selanjutnya dicari kondisi terbaik proses hibrid adsorpsi dan UF-SA dengan cara mengatur dosis optimum (dinaikkan maupun diturunkan), sehingga didapatkan tiga variasi dosis. Analisis kandungan BO dilakukan melalui pengukuran parameter Dissolved Organic Carbon (DOC), $\mathrm{UV}_{254}, \mathrm{E}_{4} / \mathrm{E}_{6}$, dan $\mathrm{UV}_{456}$ menggunakan TOC Analyzer dan Spektrofotometer UV serta karakterisasi membran dengan permeabilitas. Hipotesis dari penelitian ini adalah pra-perlakuan adsorpsi karbon aktif berpengaruh untuk mereduksi fouling pada membran UFSA, dan model Modified Fouling Index (MFI) dapat menggambarkan pembentukan fouling pada proses hibrid adsorpsi dan UF-SA pada penyisihan air efluen.
\end{abstract}

Kata kunci: Adsorpsi, Efluen IPAL Domestik, BO, Fouling, Ultrafiltrasi

\begin{abstract}
One service that produces ultrafiltration (UF) performance is membrane fouling. The existence of Organic Materials (BO) is one of the main causes of membrane fouling in Domestic WWTP water. Therefore, it is necessary to pre-treatment the activated carbon adsorption to reduce fouling and improve the performance of UF membranes. This study aims to determine the water treatment process with hybrid adsorption and Ultrafiltration (UF) cellulose acetate (SA) processes, and analyze the process of forming fouling membranes in the hybrid adsorption and UF-SA processes. The activated carbon used in this study was Activated Carbon Powder (PAC) with an interval of $25 \mathrm{mg} / \mathrm{L}$ in the range of $25 \mathrm{mg} / \mathrm{L}-200 \mathrm{mg} / \mathrm{L}$ and $\mathrm{pH}$ 4. The method used for the treatment process was stirring $180 \mathrm{rpm}$ adsorption for 240 minutes. Then, flowing to the UF-SA membrane uses a dead-end flow system with an operating value of 1-3 bar at an interval of 0.5 bar at $p H 4$ for 120 minutes. The right process is hybrid adsorption and UF-SA by setting the optimum dose (raised or lowered), in the same amount. BO content analysis was carried out through Dissolved Organic Carbon (DOC), $U V_{254}, E_{4} / E_{6}$, and $U V_{456}$ parameters using TOC Analyzer and UV Spectrophotometer and membrane characterization with permeability. The hypothesis of this study is the pre-washing of activated carbon to
\end{abstract}


reduce fouling on UF-SA membranes, and the Modified Fouling Index (MFI) model can be used in hybrid adsorption and UF-SA processes in effluent air allowance.

Keywords: Adsorption, Effluent IPAL Domestic, BO, Fouling, Ultrafiltration

\section{PENDAHULUAN}

Air limbah domestik mengandung senyawa organik yang dapat menurunkan kualitas air, sehingga diperlukan suatu pengolahan agar tidak mencemari lingkungan (Supradata, 2005). Bahan Organik (BO) dalam air limbah domestik IPAL merupakan salah satu parameter kunci kualitas air yang mempengaruhi proses pada pengolahan air (Sami, 2012). Keberadaan BO pada air efluen dapat menyebabkan warna, bau dan pertumbuhan kembali biologi pada jaringan distribusi air yang menyebabkan terbentuknya produk samping dari desinfeksi berupa senyawa karsinogen (Tang dkk., 2014; Zularisam dkk., 2009).

Metode yang dapat digunakan untuk menyisihkan BO pada air efluen IPAL adalah teknologi membran ultrafiltrasi (UF). Beberapa penelitian melaporkan membran UF mampu menyisihkan kandungan BO pada air (Herwati dkk., 2015; Wardani, 2013; Syarfi, 2007; Notodarmojo dan Deniva, 2004). Meskipun membran berpotensi dalam pengolahan air, akan tetapi dalam penerapannya ditemukan satu masalah utama yakni terjadinya fouling (Zularisam dkk., 2006). Fouling dapat menurunkan fluks membran (Zularisam dkk., 2007), menurunkan kinerja membran, meningkatkan biaya operasi, dan seringnya pencucian membran (Mahmud dan Noor, 2005). BO merupakan faktor utama penyebab fouling membran UF pada air permukaan (Arhin dkk., 2016; Gao dkk., 2011; Campinas dan Rosa, 2010). Fraksi hidrofilik BO berkontribusi besar pada fouling membran (Malczewska dan Benjamin, 2016; Zularisam dkk., 2006). Kim dkk. (2008) menyebutkan karbon aktif dapat menyisihkan BO dengan berat molekul kecil, yaitu fraksi hidrofilik. Oleh karena itu adsorpsi karbon aktif dengan $P A C$ dapat menjadi salah satu alternatif untuk mengurangi fouling membran.

Proses adsorpsi pada membran UF dapat menyisihkan kontaminan organik seperti Total Organic Carbon (TOC) (Kim dkk., 2008), Dissolved Organic Carbon (DOC) atau kontaminan pada air (Mozia dkk., 2005). Karbon aktif merupakan adsorben yang sering digunakan pada proses hibrid adsorpsi-UF karena kemampuannya yang bagus dalam menyisihkan kontaminan serta ketersediaannya mudah didapat (Gao dkk., 2011). Beberapa penelitian melaporkan pra-perlakuan adsorpsi pada UF dapat meningkatkan fluks, kinerja filtrasi lebih lama dan mengurangi frekuensi pencucian membran secara kimia (Lee dkk., 2007; Konieczny dan Klomfas, 2002).

Selulosa asetat (SA) atau celloluse acetate merupakan bahan pertama pembuat membran asimetrik dengan sifat ketahan yang baik terhadap bahan kimia. Membran ini termasuk dalam kelompok membran yang tidak bermuatan (Sivakumar dkk., 2006). Membran ultrafiltrasi dari selulosa asetat digunakan untuk menghilangkan koloid dan partikel dengan modul higienis. Keunggulan membran selulosa asetat antara lain cocok untuk sampel yang didasari kandungan air, membran selulosa asetat mengikat sedikit protein, laju alir permeat (fluks) tinggi, relatif kuat dan tidak larut dalam alkohol (Hakim, 2012). Uji pendahuluan yang dilakukan pada tanggal 09 April 2018 diperoleh karakteristik efluen IPAL PD PAL mencakup DO (Dissolve Oksigen), TDS (Total Dissolve Solid), pH, Suhu dan $\mathrm{UV}_{254}$. Dapat dilihat pada Tabel 2.1 
Tabel 2.1. Karakteristik Efluen IPAL Pekapuran Raya (Uji Pendahuluan).

\begin{tabular}{ccccc}
\hline Parameter & Pekapuran & $\begin{array}{c}\text { Konsentrasi } \\
\text { Xue dkk., } \\
(2014)\end{array}$ & $\begin{array}{c}\text { Gouttal dkk., } \\
(2018)\end{array}$ \\
\hline 1. & $\mathrm{pH}$ & $5.6-7.1$ & $7.1-7.5$ & $8.3-8.5$ \\
2. & $\mathrm{Suhu}$ & $26.0-29.3$ & - & - \\
3. & $\mathrm{DO}(\mathrm{mg} / \mathrm{L})$ & $1.10-2.25$ & - & - \\
4. & $\mathrm{DOC}(\mathrm{mg} / \mathrm{L})$ & 9.059 & $9.3-11.9$ & - \\
5. & $\mathrm{TDS}(\mathrm{mg} / \mathrm{l})$ & $197.5-216.0$ & 0.115 & - \\
6. & $\mathrm{UV}_{254}(1 / \mathrm{cm})$ & $0.130-0.197$ & $0.115-0.216$ & $0.186-0.312$ \\
\hline
\end{tabular}

\section{METODE PENELITIAN \\ Pengambil Sampel Air Efluen}

Mengambil sampel air Air efluen IPAL sebagai sampel penelitian berasal dari Jalan Pasar Pagi Nomor 89 RT 02, Kota Banjarmasin, Kalimantan Selatan. Kemudian sampel dilakukan dengan menadah efluen kemudian dimasukkan kedalam beberapa jerigen, menyimpan dan menghomogenkan sampel dalam ember plastik. Melakukan karakterisasi sampel air efluen dengan parameter meliputi: Suhu, DO, pH, TDS dan $\mathrm{UV}_{254}$.

\section{Karakterisasi Sampel Air Efluen}

Karakterisasi efluen IPAL dilakukan di Laboratorium Lingkungan Fakultas Teknik Universitas Lambung Mangkurat, Laboratorium Kesehatan Provinsi Kalimantan Selatan dengan memeriksa parameter air meliputi Suhu, pH, TSS, TDS dan BOD, UPTD Laboratorium Kota Banjarmasin memeriksa parameter air meliputi uji E. Coli serta Laboratorium Kimia dan Lingkungan Industri Pertanian Fakultas Pertanian Universitas Lambung Mangkurat memeriksa uji $\mathrm{UV}_{254}$, UV $\mathrm{UV}_{46} / \mathrm{UV}_{656}$, dan $\mathrm{UV}_{456 .}$

\section{Pembuatan Membran Ultrafiltrasi Selulosa Asetat}

Pembuatan membran ultrafiltrasi selulosa asetat yang dilakukan pada penelitian ini menggunakan teknik inversi fasa dengan menggunakan proses rendam endap. Pembuatan membran dilakukan dalam dua tahap, yaitu pembuatan larutan cetak (dope), dan pencetakan membran.

\section{Pembuatan larutan cetak (dope)}

Membran yang dibuat dalam penelitian ini merupakan membran ultrafiltrasi terbuat dari polimer selulosa asetat $11 \%(\mathrm{~b} / \mathrm{b})$, aseton $59 \%(\mathrm{~b} / \mathrm{b})$, dan dimetil formamida $30 \%(\mathrm{~b} / \mathrm{b})$. Komposisi ini diperoleh dari penelitian Rahman (2014) dan seluruh zat yang dicampur dikonversi dalam satuan berat. Bahan berbentuk cair seperti dimetil formamida dan aseton dimasukkan kedalam Erlenmeyer kemudian diaduk dengan menggunakan magnetic stirrer. Selulosa asetat dimasukan sedikit demi sedikit kedalam larutan tersebut. Larutan diaduk sekitar 8 jam agar semua bahan menjadi homogen. Setelah proses pengadukan selesai, larutan membran tersebut disimpan terlebih dahulu selama 12 jam dalam lemari pendingin sebelum kemudian dicetak menjadi lembaran membran.

\section{Pencetakan membran}

Mencetakan membran menggunakan teknik inversi fasa, yaitu dengan proses rendam endap. proses pembuatan membran adalah mencetaknya pada sebidang kaca yang sudah diberi pembatas berupa selotip dikedua sisinya. Pembatas tersebut bertujuan agar tebal membran yang dibuat seragam. Dalam pembuatan alat pencetak tersebut tidak boleh ada gelembung udara yang terjebak dalam selotip sebab itu akan mempengaruhi proses pencetakan membran. Saat dipakai 
kaca harus dalam keadaan kering dan bersih karena akan berpengaruh terhadap kualitas membran yang dibuat (Rahman, 2014). Membran yang sudah dicetak kemudian didiamkan sekitar 30 detik agar pelarutnya menguap, lalu membran dicelupkan kedalam akuades (teknik presipitasi). Setelah terlepas dari kaca, membran direndam selama 1 jam agar pelarutnya/aseton yang tersisa menguap dan mencapai kestabilan pori membran, kemudian membran direndam dengan air hangat selama 30 menit untuk memperkuat membran. Langkah berikutnya membran yang sudah direndam dibilas lagi untuk menghilangkan aseton yang masih terjebak didalam membran. Membran kemudian dicetak sesuai dengan bentuk alat filtrasi membran dan disimpan dalam wadah tertutup yang berisi larutan formalin 1\% (Rahman,2014).

\section{Karakterisasi Membran}

Membran yang telah dibuat kemudian dikarakterisasi dengan menggunakan permeabilitasnya. Caranya yaitu dengan mengalirkan akuades melalui permukaan membran dan dihitung volume permeat setiap 10 menit selama 60 menit dan diberikan variasi tekanan. Penentuan permeabilitas dilakukan dengan menggunakan alat sel filtrasi sistem aliran dead-end. Meletakkan kertas saring dan membran yang telah dipotong ke dalam sel filtrasi untuk mengukur fluksnya. Kemudian, memasukkan akuades ke dalam sel filtrasi kemudian sel ditutup rapat dan diberikan tekanan udara dengan variasi 1, 1.5, 2, 2.5, dan 3 bar. Setelah itu permeat yang keluar ditampung selama selang waktu 300 menit dan diukur volumenya dengan interval 10 menit. Pengukuran dilakukan sampai didapatkan volume yang konstan.

\section{Percobaan Penentukan Dosis Terbaik Proses Adsorpsi}

Penentuan dosis optimum pada proses adsorpsi BO menggunakan karbon aktif PAC mengacu pada metode penelitian Aziza (2013). Prosedur penelitian yang dilakukan yaitu, pertama memasukkan sampel air efluen yang telah dikarakterisasi sebanyak $200 \mathrm{~mL}$ ke dalam labu Erlenmeyer $250 \mathrm{~mL}$. Mengatur $\mathrm{pH}$ sampel air efluen menjadi 4 dengan cara menambahkan $\mathrm{NaOH}$ 0,05 N. Selanjutnya, menambahkan karbon aktif PAC dengan dosis bervariasi pada interval 25 $\mathrm{mg} / \mathrm{L}$ yaitu $25 \mathrm{mg} / \mathrm{L}-200 \mathrm{mg} / \mathrm{L}$. Melakukan pengadukan menggunakan rotary shaker $180 \mathrm{rpm}$ dengan waktu kontak 240 menit. Waktu kontak merupakan faktor yang menentukan pada proses adsorpsi. Kemudian menyaring sampel air efluen yang telah diolah menggunakan kertas saring ukuran pori $0,45 \mu \mathrm{m}$ dan alat vacum filter untuk memisahkan sampel air efluen dengan adsorben. Melakukan percobaan ini sebanyak 3 kali. Kemudian melakukan analisis $\mathrm{UV}_{254}, \mathrm{UV}_{456 /} \mathrm{UV}_{656}$ dan $\mathrm{UV}_{456}$ menggunakan UV-Vis Spectrofotometer.

\section{Percobaan Proses Hibrid Adsorpsi dan UF-SA}

Setelah mendapatkan dosis terbaik pada proses pra-perlakuan adsorpsi BO, selanjutnya melakukan tahap aplikasi pra-perlakuan dan ultrafiltrasi dengan tiga kali pengulangan sehingga nantinya akan dilakukan 15 kali percobaan. Tahapan proses hibrid adsorpsi dan UF-SA, yaitu meletakkan kertas saring Whatman No.41 sebagai support di bawah dan di atas membran dan meletakkan membran ke dalam sel ultrafiltrasi. Merangkai alat ultrafiltrasi dan memasukkan sampel air efluen yang telah dilakukan pra-perlakuan sebagai umpan sebanyak $\pm 200 \mathrm{~mL}$. Mengoperasikan alat filter membran dengan variasi tekanan 1, 1.5, 2, 2.5, dan 3 bar dengan $\mathrm{pH} 4$ dalam waktu 60 menit dan setiap 10 menit diukur volume air yang diolah (volume permeat) dan 300 menit untuk melihat seberapa besar fouling yang terjadi. Sistem aliran yang digunakan adalah dead-end. Selanjutnya melakukan analisis permeat untuk mengetahui parameter yang diteliti, yaitu $\mathrm{UV}_{254}, \mathrm{E}_{4} / \mathrm{E}_{6}$, dan $\mathrm{UV}_{456}$ dengan UV-Vis Spectrofotometer. 
Setelah mendapatkan tekanan operasi terbaik pada membran. Selanjutnya adalah melakukan percobaan dengan mengalirkan air umpan sebanyak $\pm 200 \mathrm{~mL}$ menggunakan tekanan operasi terbaik yang didapatkan sebelumnya dan melakukan variasi dosis terbaik (5 variasi) pada dosis praperlakuan (adsorpsi) untuk mengetahui dosis yang tepat pada kondisi operasi terbaik dalam menurunkan potensi pembentukan fouling membran. Langkah akhir, melakukan analisis permeat untuk mengetahui parameter yang diteliti.

\section{Analisis Data}

Hasil yang didapat adalah data air efluen IPAL sebelum dan setelah pra-perlakuan variasi kecepatan pengadukan dan setelah proses penyaringan dengan membran ultrafiltrasi. Dari data tersebut selanjutnya akan disajikan dalam bentuk tabel dan grafik.

\section{MFI (Modified Fouling Index) dan Pore Blocking}

Perhitungan MFI dan Pore blocking digunakan untuk memprediksi potensi fouling pada umpan dalam sistem membran. Nilai pore blocking ditentukan dari gradien umum persamaan filtrasi pada tekanan konstan menggunakan plot $\mathrm{t} / \mathrm{V}$ terhadap waktu $(\mathrm{t})$.

\section{Kurva Saturated}

Persamaan kurva saturated menunjukkan pola kurva jenuh yang digunakan untuk mengidentifikasi sifat fouling dalam penelitian ini:

$$
V=V \max +\frac{t}{k f+t}
$$

$$
\text { dimana: } \begin{aligned}
\mathrm{V} & =\text { Volume permeat }(\mathrm{L}) \\
\operatorname{Vmax} & =\text { Nilai potensi fouling } \\
\mathrm{t} & =\text { Waktu filtrasi }(\mathrm{s}) \\
k f & =\text { ketetapan filtrasi }
\end{aligned}
$$

\section{HASIL DAN PEMBAHASAN}

Karakteristik Sampel Air Efluen

Hasil analisis karakterisasi air efluen yang diambil di Jalan Pasar Pagi Nomor 89 RT 02, Kalimantan Selatan disajikan pada Tabel 4.1. secara visual air gambut yang digunakan pada penelitian ini berwarna keruh dan terdapat endapan. Warna tersebut disebabkan oleh keberadaan zat organik terlarut yang tinggi pada air gambut.

Tabel 4.1 Hasil Karakterisasi Air Efluen

\begin{tabular}{ccccccccc}
\hline \multirow{2}{*}{ No } & \multirow{2}{*}{ Parameter } & \multirow{2}{*}{ Satuan } & \multicolumn{7}{c}{ Minggu ke- } & \multirow{2}{*}{ Rata-rata } \\
\hline 1 & DOC & $\mathrm{Mg} / \mathrm{L}$ & 9,059 & - & - & - & - & 9,059 \\
2 & $\mathrm{UV}_{254}$ & $1 / \mathrm{cm}$ & 0,185 & 0,195 & 0,197 & 0,193 & 0,190 & 0,192 \\
3 & $\mathrm{UV}_{456}$ & $1 / \mathrm{cm}$ & 0,093 & 0,095 & 0,092 & 0.094 & 0,097 & 0,094 \\
4 & $\mathrm{E}_{4} / \mathrm{E}_{6}$ & - & 1,4 & 1,3 & 1,4 & 1,4 & 1,4 & 1,4 \\
5 & $\mathrm{SUVA}$ & L/mg.m & 2.042 & 2.152 & 2.174 & 2.130 & 2.097 & 2.119 \\
6 & $\mathrm{pH}$ & - & 7,2 & 7,2 & 7,3 & 7,3 & 7,3 & 7,26 \\
\hline
\end{tabular}

Kandungan DOC dan zat organik $\left(\mathrm{UV}_{254}\right)$ yang digunakan pada penelitian ini relatif tinggi untuk air efluen seperti yang ditunjukan pada tabel 4.1. Hasil tersebut sesuai dengan karakterisasi air efluen yang dilaporkan Xue., dkk (2014) dan Gouttal., dkk (2018) dengan rentang 9,3 - 11,9 mg/L (DOC) dan 0,115 $0,3121 / \mathrm{cm} \mathrm{UV}_{254}$ (zat organik). Hasil pengukuran $\mathrm{UV}_{254}$ pada minggu ke-I sampai minggu ke-V 
menunjukan bahwa zat organik yang pada air efluen mengalami perubahan relatif kecil terhadap waktu (Tabel 4.1). perubahan tersebut terjadi akibat partikel zat organik yang mengendap. Oleh karena itu, air efluen tersebut cukup representatif untuk digunakan pada penelitian ini karena pengaruh perubahan BO terhadap waktu relatif kecil.

Berdasarkan tabel 4.1 diketahui nilai $\mathrm{UV}_{254}$ yang digunakan pada penelitian ini realtif kecil dibandingkan dengan nilai UV $_{254}$ yang dilaporkan oleh Xue., dkk (2014) dan Gouttal., dkk (2018) berkisar antara 0,115 $0,3121 / \mathrm{cm}$. hal tersebut terjadi karena lokasi pengambilan sampel berbeda dengan penelitian-penelitian sebelumnya sehingga karakteristik air efluen yang digunakan merupakan senyawa aromatik yang bukan dominan hidrofobik. Nilai $\mathrm{UV}_{254}$ pada minggu ke-I sampai minggu ke-V mengalami perubahan relatif kecil terhadap waktu (Tabel 4.1). Parameter SUVA mengindikasikan karakter aromatik pada air permukaan. Nilai SUVA pada tabel 4.1 sebesar 2,119 L/mg.m berarti BO merupakan hidrofobik dan hidrofilik dengan bm campuran sesuai teori Edzwald dan Tobiason (1999). Nilai SUVA pada penelitian ini berbeda dengan penelitian yang dilaporkan Mahmud dkk. (2012) yang memiliki BO aromatik dominan hidrofobik. Hal tersebut terjadi seperti yang dijelaskan pada parameter $\mathrm{UV}_{254}$ sebelumnya, karena parameter SUVA memiliki hubungan terhadap $\mathrm{UV}_{254}$ dan DOC. Rendahnya nilai $\mathrm{UV}_{254}$ dan SUVA pada air efluen yang diuji mengindikasikan tingginya fraksi hidrofilik, hal ini mungkin disebabkan kontaminasi air efluen akibat aktivitas manusia disekitar lokasi penelitian.

Nilai $\mathrm{pH}$ air efluen pada penelitian ini cenderung netral sebesar 7,26 pada pengkuran dilapangan. Berdasarkan tabel 4.1, diketahui nilai $\mathrm{pH}$ air efluen dari minggu ke-I sampai minggu ke-V mengalami sedikit kenaikan yang diakibatkan dari BO dari air efluen yakni 7,2-7,3. Hal ini cenderung sama dengan hasil yang dilaporkan Xue., dkk (2014) dan Gouttal., dkk (2018) dengan nilai pH berkisar antara 7,1-8,5.

\section{Permeabilitas Membran Ultrafiltrasi Selulosa Asetat}

Karakterisasi membran secara fungsional dilakukan melalui pehitungan fluks akuades untuk melihat permbablitas membran yang disajikan pada gambar 4.2 kecenderungan yang terjadi adalah semakin besar tekanan operasi, maka nilai fluks yang dihasilkan juga semakin meningkat. Berdasarkan Gambar 4.2, nilai fluks akuades berada pada rentang $36,7-190.0 \mathrm{~L} / \mathrm{m}^{2} . j \mathrm{am}$, dengan nilai fluks tertinggi terjadi pada tekanan 3 bar, sedangkan fluks terendah terjadi pada tekanan 1 bar. Hal tersebut terjadi sesuai dengan teori gaya dorong (driving force) dari operasi membran.



Gambar 4.1 Grafik hubungan antara fluks akuades terhadap tekanan

Konstanta permeabilitas membran UF menurut Mulder (1996) adalah 49,4 L/m².jam.bar - 493,5 $\mathrm{L} / \mathrm{m}^{2}$.jam.bar, dan jika merujuk kepada Wenten (1999) nilai permeabilitas UF berkisar antara 20 L/m².jam.bar - $200 \mathrm{~L} / \mathrm{m}^{2}$.jam.bar. pada Gambar 4.2 ditunjukkan nilai permeabilitas membran UF-SA 
sebesar 71,03 L/m².jam.bar. Sesuai dengan literatur, maka membran UF-SA yang telah dibuat dapat dikategorikan sebagai membran UF.

\section{Analisis Morfologi Membran Ultrafiltrasi Selulosa Asetat}

Hasil analisa morfologi membran SA pada peneltian ini menggunakan SEM yang ditunjukkan pada gambar 4.2 (a dan b). permukaan datar dari membran SA sebelum digunakan dengan pori yang terlihat jelas menunjukkan bahwa membran tersebut diidentifikasi memiliki struktur membran asimetrik. Membran asimetrik merupakan membran yang tersusun oleh beberapa lapisan. Struktur membran asimetrik terdiri atas lapisan yang sangat padat dan lapisan berpori sebagai penyangga.

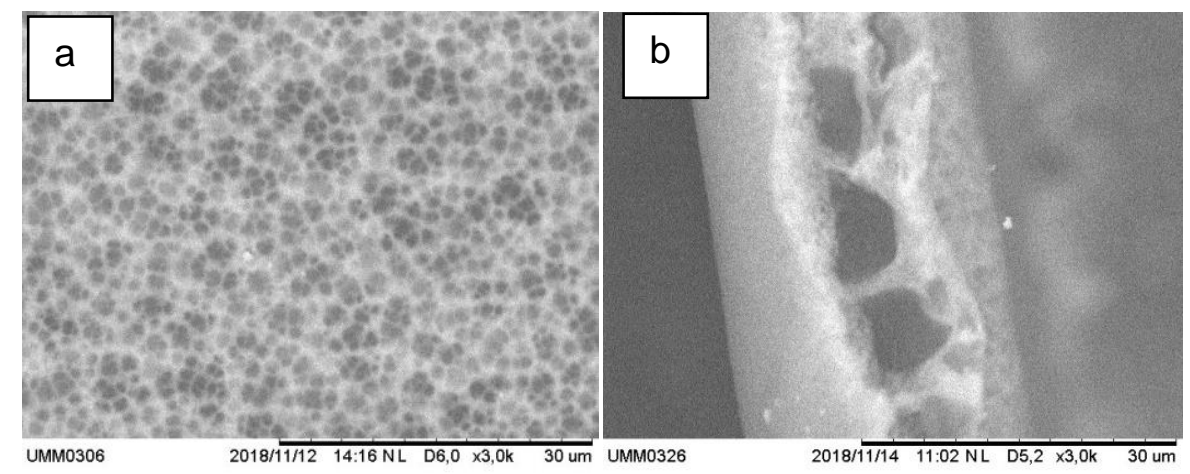

Gambar 4.2 Foto SEM membran SA sebelum digunakan (a) tampak permukaan dan (b) melintang

Hasil foto SEM yang ditunjukan pada gambar 4.2 (a) yaitu permukaan datar membran dengan 3.000 kali dan memiliki pori kurang dari $30 \mu \mathrm{m}$ berdasarkan skala yang ditunjukkan pada Gambar 4.2. namun dari hasil tersebut tidak dapat ditentukan secara pasti berapa ukuran pori pada membran yang harusnya dilakukan dengan software Image-J yang merujuk pada penelitian Kurniawan dkk.,(2011). Ukuran pori membran UF berkisar antara 1-100 $\mathrm{nm}(0,001-0,1 \mu \mathrm{m})$ merujuk pada mulder (1996). Bersadarkan literatur tersebut maka membran UF yang digunakan pada penelitian ini dapat dikategorikan sebagai membran UF.

Secara visual fouling membran pada penelitian ini dapat dilihat melaui foto SEM seperti yang ditunjukkan Gambar 4.3. Hasil foto SEM membran UF setelah diletwatkan air efluen dengan pra-perlakuan adsorpsi memiliki ukuran pori kurang dari $30 \mu \mathrm{m}$ dan perbesaran 3.000 kali. Ukuran pori membran yang cukup besar tersebut merupakan lubang yang terdapat pada permukaan membran UF pada tekanan operasi 3 bar. Fenomena tersebut sama dengan yang dilaporkan oleh Khalisa dkk. (2017), bahwa lubang yang terdapat pada permukaan membran terjadi akibat proses filtrasi. Lubang tersebut tertutupi oleh partikel kontaminan sehingga meningkatkan efisiensi dalam peningkatan kinerja membran.

Hasil foto SEM pada Gambar 4.3 (b) menunjukkan bahwa permukaan membran UF yang telah dilewatkan air umpan memiliki lapisan atas yang lebih tebal dibandingkan dengan hasil foto SEM membran sebelum digunakan. Hal tersebut menunjukkan bahwa terbentuknya lapisan cake pada permukaan membran akibat keberadaan BO dalam air efluen. Pada Gambar 4.3 terdapat macrovoid (rongga besar) pada membran UF setelah digunakan. Fenomena ini sepeti yang dijelaskan Khalisa dkk. (2017) bahwa morfologi membran dipengaruhi oleh proses pertukaran pelarut dan non pelrut pada bak koagulan saat pencetakan membran. Sehingga pori yang terbentuk tidak merata dan membentuk rongga besar pada membran. 


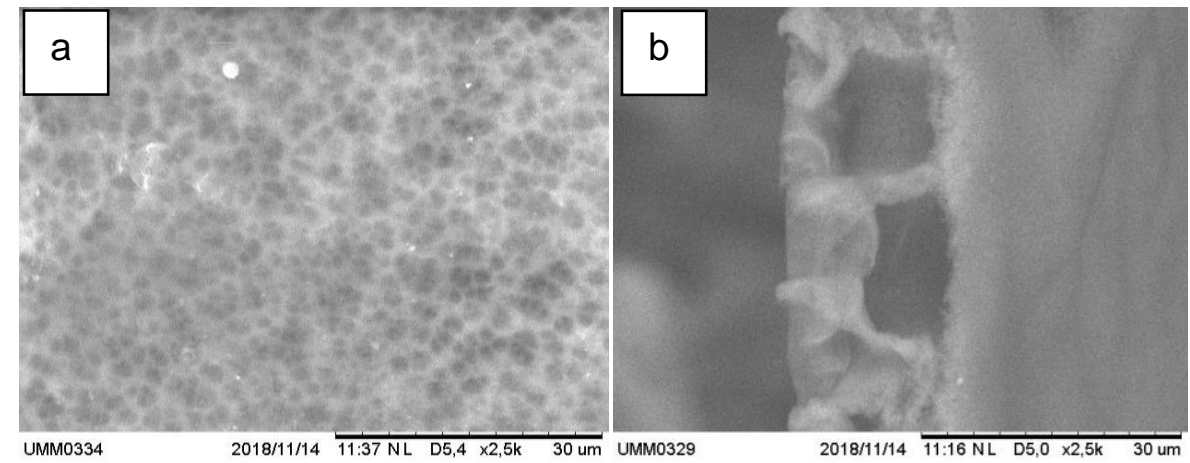

Gambar 4.3 Foto SEM membran SA setelah dilewatkan permeat (a) tampak permukaan dan (b) melintang

\section{Proses Pra-Perlakuan Adsorpsi Karbon Aktif}

\section{Pengaruh pH Terhadap Proses Pra-Perakuan Adsorpsi}

Variasi pH pada proses adsorpsi air efluen akan mempengaruhi tingkat penyisihan $\mathrm{BO}$ dalam penentuan dosis optimum. Hubungan antara presentase penyisihan $\mathrm{BO}$ dengan $\mathrm{pH}$ adsorpsi disajikan pada Gambar 4.3. kecenderungan yang terjadi adalah semakin tinggi $\mathrm{pH}$ maka tingkat penyisihan $\mathrm{BO}$ cenderung menurun. Penyisihan $\mathrm{UV}_{254}$ paling tinggi terjadi pada $\mathrm{pH} 3$ sebesar 85,26\% dengan nilai $\mathrm{UV}_{254}$ awal, sedangkan presentase penyisihan paling rendah terjadi pada $\mathrm{pH} 7$ sebesar 33,58\%. Begitu pula dengan zat organik $\mathrm{UV}_{456}$ pada $\mathrm{pH} 3$ sebesar $82,84 \%$ dan $\mathrm{pH} 7$ sebesar $59,31 \%$.



Gambar 4.3 Grafik Hubungan antara presentase penyisihan BO terhadap pH

Pola yang ditunjukan pada Gambar 4.3 adalah kenaikan $\mathrm{pH}$ berbanding terbalik dengan tingkat penyisihan BO pada proses adsorpsi. Hasil penelitian ini cenderung sama dengan hasil penelitian Aziza (2013); Lu dan $\mathrm{Su}$ (2007) yang menyatakan proses adsorpsi bekerja optimal pada $\mathrm{pH}$ rendah (asam). $\mathrm{pH}$ adsorpsi cenderung meningkat mendekati netral, kecuali pada pH 3 (Gambar 4.8). penambahan karbon aktif kedalam air efluen akan terjadi reaksi pelepasan $\mathrm{OH}^{-}$pada larutan, sehingga $\mathrm{pH}$ akan mengalami pengingkatan. Hasil penelitian ini sesuai dengan penelitian Aziza (2013). pH optimum adsorpsi terjadi pada $\mathrm{pH} 4$ dengan presentase penyisihan BO yang cukup besar 81,35\% ( $\left.\mathrm{UV}_{254}\right), 80,39\left(\mathrm{UV}_{456}\right)$.

Uji rasio $\mathrm{E}_{4} / \mathrm{E}_{6}$ dilakukan untuk mempresentasikan ukuran molekul pada air efluen. Pada Gambar 4.3 dapat dilihat bahwa rasio $\mathrm{E}_{4} / \mathrm{E}_{6}$ memiliki hubungan terbalik dengan persen penyisihan $\mathrm{UV}_{254}$ dan $\mathrm{UV}_{456}$. Rasio $\mathrm{E}_{4} / \mathrm{E}_{6}$ cenderung meningkat seiring dengan semakin besarnya nilai $\mathrm{pH}$. Nilai rasio $\mathrm{E}_{4} / \mathrm{E}_{6}$ yang kecil mengindikasikan penyisihan $\mathrm{BO}$ pada air efluen didominasi dengan ukuran molekul yang besar. Persen penyisihan $\mathrm{UV}_{254}$ dan $\mathrm{UV}_{456}$ memiliki kecenderungan menurun seiring dengan besarnya nilai $\mathrm{pH}$. Pada $\mathrm{pH}$ 3 dan 7, persen penyisihan rasio $\mathrm{E}_{4} / \mathrm{E}_{6}$ yaitu $48,07 \%$ dan $64,03 \%$. 


\section{2. $\quad$ Pengaruh Dosis Karbon Aktif Pada Pra-Perlakuan Adsorpsi}

Penambahan dosis adsorben berpengaruh terhadap tingkat penyisihan $\mathrm{BO}$ air efluen. Hasil penyisihan $\mathrm{UV}_{254}$ dan $\mathrm{UV}_{456}$ pada penentuan dosis optimum proses adsorpsi ditunjukan pada Gambar 4.3. kecenderungan yang terjadi adalah semakin besar penambahan adsorben, maka tingkat penyisihan BO juga semakin meningkat.



Gambar 4.4 Grafik hubungan antara presentase penyisihan BO terhadap dosis

Pada Gambar 4.4 menunjukan penyisihan $\mathrm{UV}_{254}$ lebih besar daripada penyisihan $\mathrm{UV}_{456}$ pada dosis $25-100$ $\mathrm{mg} / \mathrm{L}$. sedangkan pada dosis $150-200 \mathrm{mg} / \mathrm{L}$ presentase penyisihan $\mathrm{UV}_{254}$ dan $\mathrm{UV}_{456}$ relatif sama. Fenomena ini seperti yang dijelaskan oleh Kim dkk. (2008) bahwa karbon aktif optimal menyisihkan BO dengan ukuran BM kecil. Sehingga penyisihan $\mathrm{UV}_{254}$ dengan kandungan BM besar dan BM kecil akan terlebih dulu tersisihkan daripada $\mathrm{UV}_{456}$ yang memiliki BM besar. Sedangkan Nilson dan DiGiano (1996) menjelaskan bahwa karbon aktif cenderung mengadsorpsi material zat organik dengan BM menengah, sehingga menyisakan sedikit ruang untuk menyerap materi zat organik dengan BM tinggi dan sangat rendah. Setelah zat organik dengan BM menengah diserap, maka penambahan dosis tidak lagi mengalami pengingkatan penyisihan zat organikv yang signifikan.

Presentase penyisihan $\mathrm{UV}_{254}$ berkisar antara 47,69\% - 84,10\% sedangkan presentase penyisihan $\mathrm{UV}_{456}$ berkisar antara 65,78\% - 81,78\% (Gambar 4.4). pola yang terjadi adalah semakin besar penambahan karbon akttif, maka presentase penyisihan BO juga semakin meningkat. Kondisi optimum proses proses adsorpsi terjadi pada $\mathrm{pH} 4$ dan dosis optimum $100 \mathrm{mg} / \mathrm{L}$ dilihat dari presentase penyisihan $\mathrm{UV}_{254}$ sebesar 78,46\% dan penyisihan $\mathrm{UV}_{456} 79,56 \%$. Pra-perlakuan adsorpsi pada membran UF mampu mengurangi BO pada air umpan, sehingga penyebab terjadinya fouling pada membran dapat direduksi.

\section{Pengaruh Proses Hibrid Adsorpsi Dan UF-SA Terhadap Fluks Permeat}

Pra-perlakuan adsorpsi pada membran UF mampu meningkatkan nilai fluks permeat dibandingkan tanpa pra-perlakuan seperti yang dilaporkan Konieczny dan Klomfas (2002), Lee dkk. (2007), Riduan (2005). Praperlakuan adsorpsi digunakan untuk menyisihkan BO pada air umpan, sehingga layer cake yang terbentuk pada permukaan membran dapat direduksi. Hal ini dibuktikan dengan tingkat penyisihan BO yang tinggi proses adsorpsi, sehingga jumlah BO pada umpan berkurang sebelum menyentuh membran.

Semakin lama waktu operasi membran, maka fluks permeat yang dihasilkan semakin rendah (Gambar 4.5). pada 5 menit pertama nilai fuks tekanan 1 bar sebesar $29,86 \mathrm{~L} / \mathrm{m}^{2}$.jam dan fluks semakin menurun hingga menit ke-120 sebesar $10,17 \mathrm{~L} / \mathrm{m}^{2}$.jam. hal tersebut juga terjadi pada tekanan 1,5 bar, 2 bar, 2,5 bar dan 3 bar. Kecenderungan yang terjadi adalah nilai fluks menurun seiring dengan lama waktu operasi. Hal ini dapat disebabkan karena adanya perbedaan bentuk dan ukuran molekul umpan serta tingkat kekasaran membran sebagai faktor yang berpengaruh terhadap penurunan fluks (Herawati dkk., 2015). 


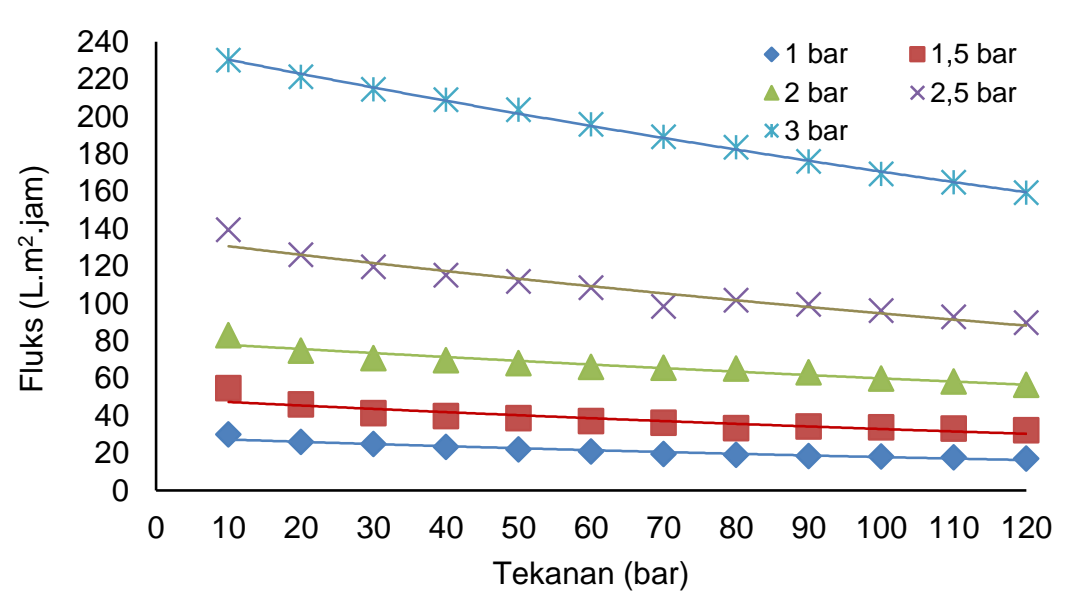

Gambar 4.5 Grafik hubungan antara fluks permeat terhadap waktu

Gambar 4.6 menunjukan bahwa tekanan berpengaruh relatif terhadap fluks. Laju fluks akan mengalami penurunan pada masing-masing tekanan seiring dengan waktu operasi. Pada waktu operasi kisaran 0 hingga 15 menit, penurunan fluks lebih tajam pada tekanan 2,5 dan 3 bar. Pada operasi diatas 15 menit, penurunan fluks relatif landai atau kecil. Sedangkan tekanan 1 bar, 1,5 bar, dan 2 bar penurunan fluks relatif landai sepanjang waktu operasi. Grafik hubungan antara fluks akuades dan fluks permeat pada masing-masing tekanan ditunjukan pada Gambar 4.6.

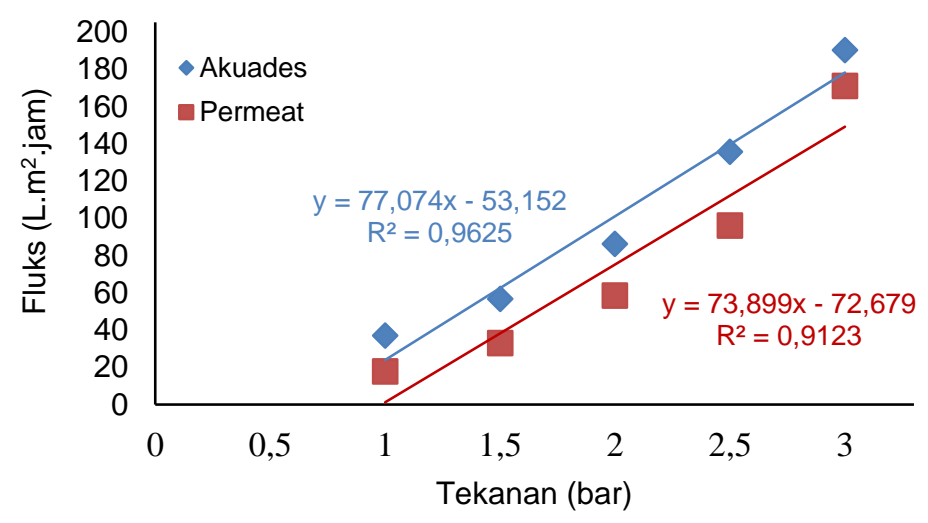

Gambar 4.6 Grafik hubungan antara fluks akuades dan fluks permeat terhadap tekanan

Penurunan nilai fluks (J) setiap menitnya mengndikasikan bahwa telah terbentuk fouling membran. Hal ini dibuktikan dari nilai fluks permeat lebih kecil dibandingkan dengan nilai fluks akuades yang cenderung lebih tinggi (Gambar 4.6). Sehingga fouling yang terjadi disebabkan oleh keberadaan BO yang memampat di permukaan membran saat melewatkan umpan air efluen. Fluks dan fouling saling berbanding terbalik. Kecenderungan yang terjadi adalah jika nilai fluks menurun, maka dipastikan fouling meningkat, begitu pula yang terjadi sebaliknya. Pola yang umumnya terjadi adalah nilai fluks yang kecil cenderung sama dengan penyisihan BO yang kecil pula seperti yang ditunjukkan Gambar 4.7. pada tekanan 1 bar, fluks permeat yang dihasilkan paling sedikit dibandingkan dengan fluks pada tekanan 1,5 bar, 2 bar, 2,5 bar, dan 3 bar. Kecilnya fluks permeat yang dihasilkan pada tekanan 1 bar cenderung sama dengan penyisihan BO yang juga kecil. Berbeda dengan 3 bar, dimana penyisihan BO paling besar dan fluks yang paling besar dibandingkan dengan tekanan 1,5 bar, 2 bar, 2,5 bar. 


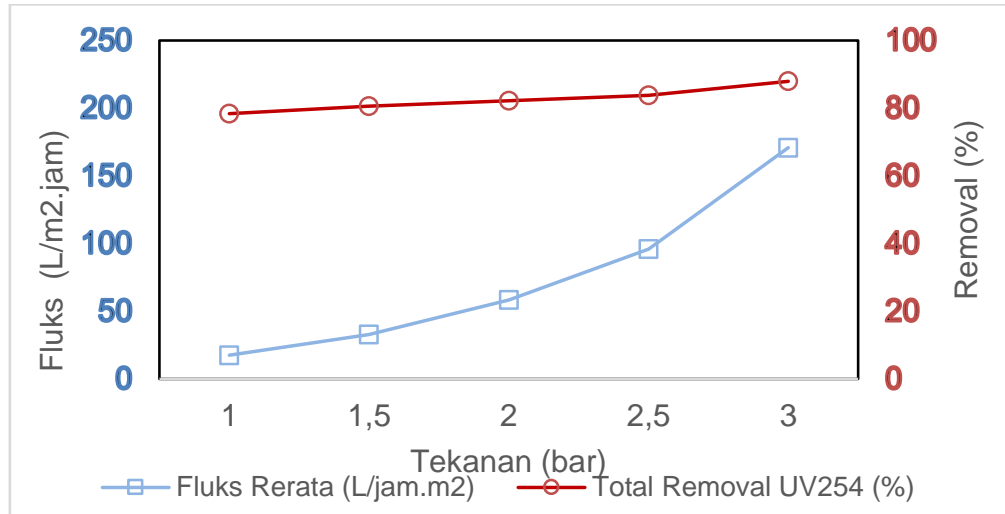

Gambar 4.7 Grafik persen penyisihan antara fluks permeat terhadap variasi tekanan untuk mengetahui tekanan optimum

Berdasarkan Gambar 4.7 dapat dilihat penyisihan BO paling tinggi terjadi pada tekanan 3 bar sebesar $87,92 \%$ dengan nlai fluks yang juga tinggi sebesar $170,828 \mathrm{~L} / \mathrm{m}^{2}$.jam. sedangkan penyisihan BO yang paling kecil terjadi pada tekanan 1 bar sebesar 78,37\% dengan nilai fluks yang juga kecil sebesar 17.564 $\mathrm{L} / \mathrm{m}^{2}$.jam. Berdasarkan literatur kecenderungan yang umumnya terjadi adalah semakin besar tekanan operasi yang diberikan, maka penyisihan pada BO akan semakin menurun, hasil ini sesuai dengan penelitian yang dilaporkan Herawati dkk., (2015). Dapat disimpulkan tekanan operasi terbaik pada proses hibrid adsorpsi dan UF-SA terjadi pada tekanan 3 bar dilihat dari perbandingan fluks permeat dan penyisihan BO terhadap tekanan pada membran UF-SA pada Gambar 4.7.

Pada saat proses adsorpsi didapatkan dosis optimum sebesar $100 \mathrm{mg} / \mathrm{L}$, pada proses hibrid adsorpsi UF-SA dosis dinaikan dan diturunkan dengan jumlah $25 \mathrm{mg} / \mathrm{L}-125 \mathrm{mg} / \mathrm{L}$ dengan interval 25 yang ditunjukkan pada Gambar 4.8. Hal ini dilakukan untuk membuktikan bahwa pada dosis $100 \mathrm{mg} / \mathrm{L}$ sudah cukup untuk menyisihkan BO pada air umpan sebanyak 78,48\% ( $\left(\mathrm{UV}_{254}\right)$ dan 54,84 (UV $\left.\mathrm{UV}_{456}\right)$. Padaa Gambar 4.8 menunjukkan penyisihan $\mathrm{UV}_{254}$ lebih besar daripada penyisihan $\mathrm{UV}_{456}$ pada dosis $25 \mathrm{mg} / \mathrm{L}-125 \mathrm{mg} / \mathrm{L}$. Setelah zat organik diserap maksimal pada dosis $100 \mathrm{mg} / \mathrm{L}$, maka penambahan dosis tidak lagi mengalami pengikatan penyisihan zat organik yang signifikan.

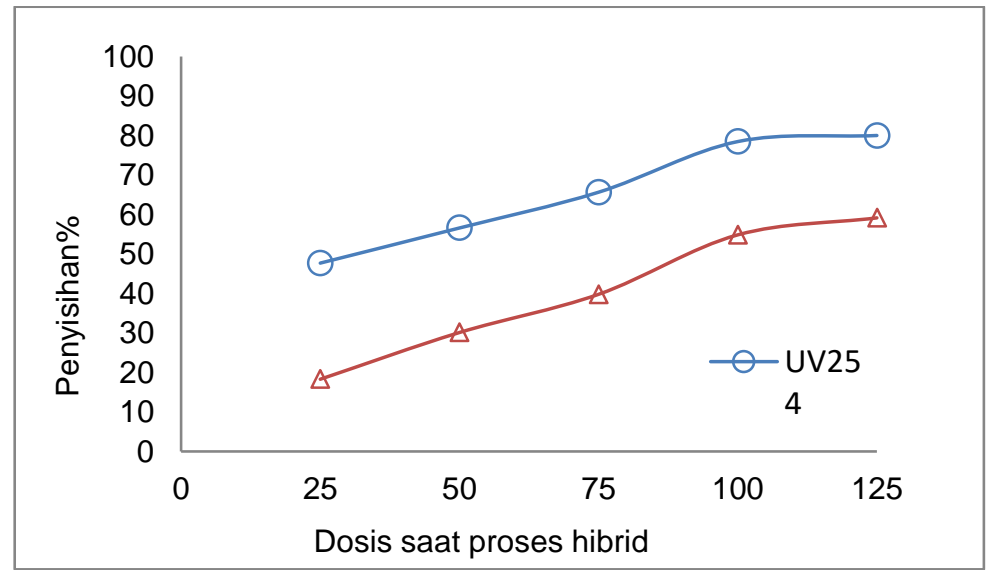

Gambar 4.8 Dosis optimum pada saat proses hibrid adsorpsi UF-SA

\section{Analisis Pembentukan Fouling Membran}

Pada penelitian ini dilakukan perhitungan MFI untuk mengetahui tingkat fouling kecil sampai yang paling besar pada masing-masing tekanan. Nilai MFI digunakan untuk memprediksi potensial fouling yang 
terjadi. MFI digambarkan sebagai gradien linier hubungan antara $\mathrm{t} / \mathrm{V}$ terhdap $\mathrm{V}$. nilai MFI berbanding lurus terhadap pembentukan fouling. Semakin besar gradien MFI, maka potensi pembentukan fouling juga semakin besar, begitu pula sebaliknya. Hasil analisis permodelan MFI dengan variasi tekanan disajikan pada Tabel 4.2

Tabel 4.2 Nilai MFI pada masing-masing tekanan

\begin{tabular}{ccc}
\hline Tekanan (bar) & MFI & $\mathrm{R}^{2}$ \\
\hline 1 & $9,336,125$ & 0,998 \\
1,5 & $1,534,838$ & 0,998 \\
2 & 177,863 & 0,984 \\
2,5 & 177,525 & 0,989 \\
3 & 92,818 & 0,996 \\
\hline
\end{tabular}

Tekanan 1 bar memiliki nilai MFI paling besar yaitu 9,336,125 dibandingkan dengan nilai MFI pada tekanan 1,5 bar, 2 bar, dan 3 bar (Tabel 4.2). Hasil permodelan MFI dapat dipakai untuk mengetahui potensial fouling yang terjadi pada proses hibrid adsorpsi dan UF-SA untuk mengetahui penyisihan BO air efluen.

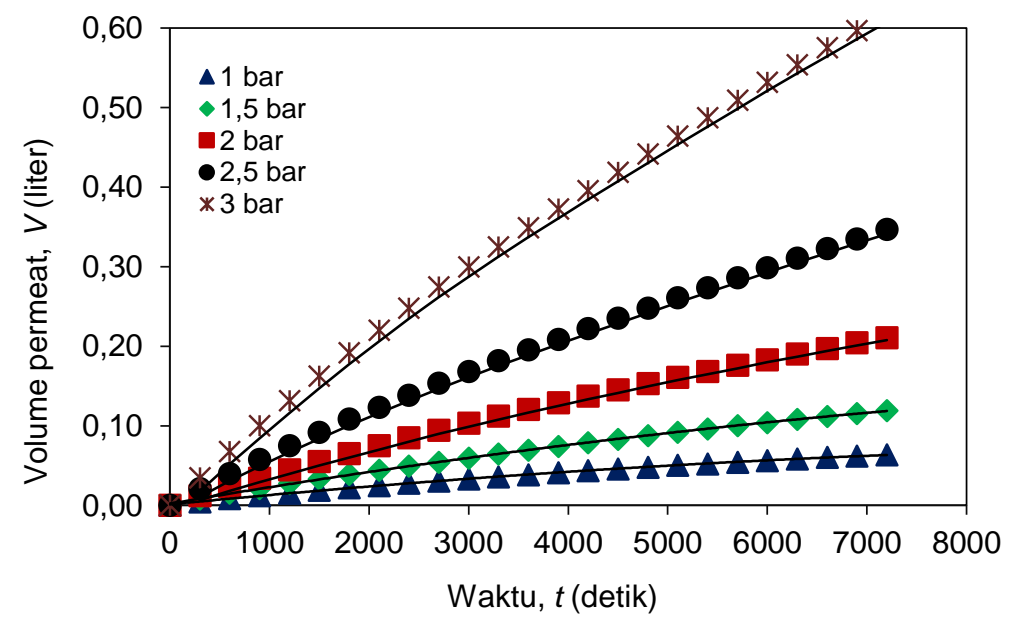

Gambar 4.7 Grafik MFI hubungan antara volume permeat terhadap waktu

Pola model MFI diatas menunjukan hasil perbandingan lurus masing-masing tekanan operasi terhadap waktu. Kecenderungan yang terjadi adalah semakin landai kurva MFI, amak potensi terjadinya fouling semakin besar pula (Gambar 4.7). jika kurva MFI tajam, maka potensi fouling yang terjadi relatif kecil terhadap waktu. Selain MFI, permodelan pore blocking juga dapat digunakan. Nilai pore blocking berbanding lurus terhdap laju penyumbatan pada pori membran. Semakin besar gradien pore blocking, maka penyumbatan pori membran juga semakin cepat, begitu pula sebaliknya.

Tabel 4.3 Nilai $S_{\mathrm{pb}}$ pada masing-masing tekanan

\begin{tabular}{ccc}
\hline Tekanan (bar) & $\mathrm{S}_{\mathrm{pb}}$ & $\mathrm{R}^{2}$ \\
\hline 1 & 6,244 & 0,988 \\
1,5 & 1,990 & 0,728 \\
2 & 1,321 & 0,986 \\
2,5 & 0,876 & 0,971 \\
3 & 0,447 & 0,992 \\
\hline
\end{tabular}


Tabel 4.3 menunjukkan Tekana n 1 bar memiliki nilai $\mathrm{S}_{\mathrm{pb}}$ yang paling besar yaitu 6,244 dibandingkan dengan nilai $S_{\mathrm{pb}}$ pada tekanan 1,5 bar, 2 bar, 2,5 bar dan 3 bar. Berdasarkan perhitungan nilai $S_{\mathrm{pb}}$ diketahui penyumbatan pori tercepat pada membran terjadi pada tekanan 1 bar, dengan $\mathrm{R}^{2}$ tertinggi yaitu 0,988 . Hasil pemodelan pore blocking juga dapat digunakan untuk memprediksi laju penyumbatan pori membran pada masing-masing tekanan. Pemodelan pore blocking digunakan untuk memprediksi laju penyumbatan pori pada membran pada jangka waktu yang panjang. Pola model pore blocking menunjukan kenaikan seiring dengan lama waktu operasi (Gambar 4.8).

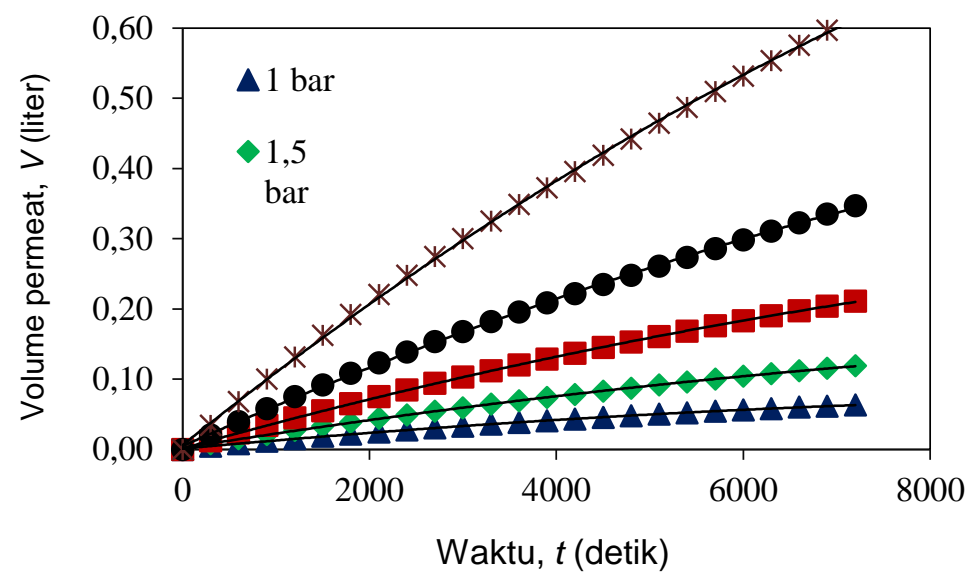

Gambar 4.8 Grafik pore blocking hubungan antara volume permeat terhadap waktu

Pemodelan kurva saturated digunakan untuk meprediksi tingkat kejenuhan membran dari cake layer yang terbentuk. Kejenuhan pada membran terjadi akibat menumpuknya BO pada permukaan membran yang mengakibatkan penurunan fluks relatif kecil dibandingkan pada menit-menit awal operasi filtrasi membran UF-SA.

Tabel 4.4 Nilai Vmax dan Kf pada masing-masing tekanan

\begin{tabular}{clc}
\hline Tekanan (bar) & Vmax & Kf \\
\hline 1 & 0,1274 & 13,79 \\
1,5 & 0,3539 & 21,50 \\
2 & 0,5698 & 22,52 \\
2,5 & 0,8424 & 19,75 \\
3 & 2,0920 & 29,70 \\
\hline
\end{tabular}

Kecenderungan yang umumnya terjadi adalah nilai Vmax dan Kf berbanding terbalik terhadap fouling membran. Semakin besar nilai Vmax dan Kf maka potensial fouling yang terjadi cukup kecil, begitu pula sebaliknya. Berdasarkan Tabel 4.4 diketahui hasil pada model kurva saturated dengan variasi tekanan menunjukkan hasil yang kurang konsisten, yaitu pada tekanan 2,5 bar memiliki nilai Vmax besar, namun tidak sebanding dengan nilai Kf yang memiliki nilai menurun. Berdasarkan hasil tersebut, maka model kurva saturated kurang mempresentasikan tingkat jenuh pada tekanan yang bervariasi. 


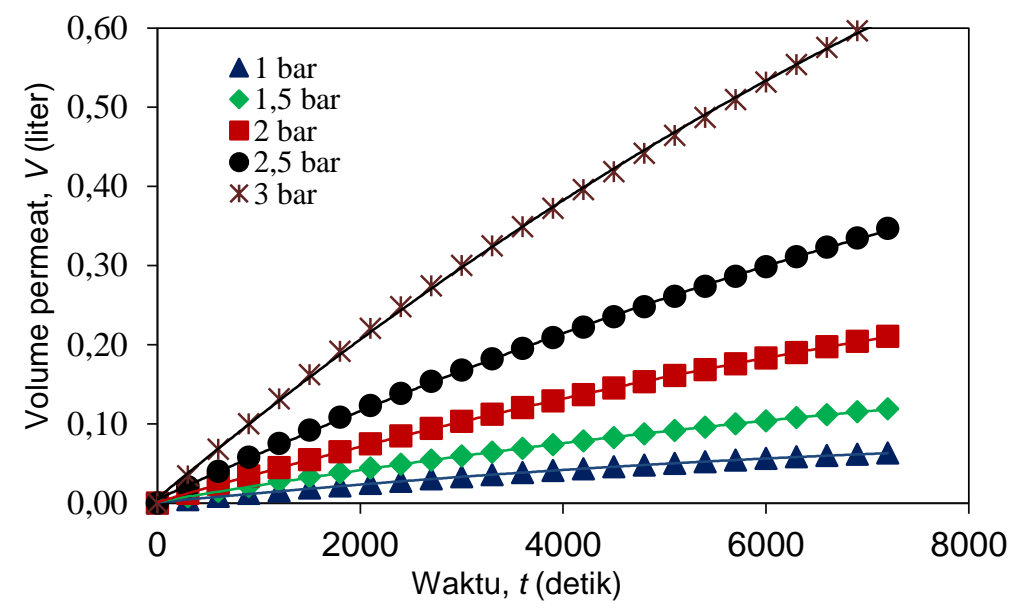

Gambar 4.9 Grafik kurva saturated hubungan antara volume permeat terhadap waktu

Pada Gambar 4.9 dapat dilihat dari tekanan 1 bar dan 1,5 bar kurva yang berbentuk tidak sesuai dengan garis kurva saturated dan oleh karena itu dapat disimpulkan pemodelan saturated tidak dapat menggambarkan potensial fouling yang terjadi pada proses hibrid adsorpsi dan UF-SA.

\section{KESIMPULAN}

Pra-relakuan adsorpsi pada membran UF mampu meningkatkan nilai fuks dibandingkan tanpa pra-perlakuan seperti yang telah banyak dilaporkan pada penelitian sebelumnya. Pada kondisi optimum pra-perlakuan adsorpsi $\mathrm{pH} 4$ dan dosis $100 \mathrm{mg} / \mathrm{L}$, mampu menyisihkan $\mathrm{BO}$ pada air umpan sebanyak 78,46\% (UV 254$)$ dan 79,56\% (UV456), sehingga dapat mengurangi terbentuknya cake pada permukaan membran yang menyebabkan fluks menurun. Pada kondisi optimum adsorpsi pada tekanan 1-3 bar diperoleh fluks tertinggi pada tekanan 3 bar sebesar $107,82 \mathrm{~L} / \mathrm{m}^{2}$.jam dengan rejeksi 87,92\% $\left(\mathrm{UV}_{254}\right)$ dan 86,03\% (UV $\left.\mathrm{UV}_{456}\right)$ merupakan kondisi tekanan operasi terbaik proses hibrid adsorpsi dan UF-SA. MFI merupakan pemodelan yang tepat untuk menggambarkan potensial fouling pada proses hibrid adsorpsi dan UF-SA pada penyisihan BO air efluen dengan $\mathrm{R}^{2}=0,998$.

\section{DAFTAR PUSTAKA}

Gao, W. H., J. M. Liang, M. Han, Z. I. Chen, Z. S. Han dan G. B. Li. (2011). Membrane Fouling Control in Ultrafiltration Technology for Drinking Water Production: A review. Desalination. 512011.

Herwati, N., Mahmud dan C. Abdi. (2015). Pengaruh pH Air Gambut Terhadap Fouling Membran Ultrafiltrasi. Jukung Jurnal Teknik Lingkungan. 1 (1) 2015. 59-73.

Kim, J. S., Z. X. Cai dan M. M. Benjamin. (2008). Effects of adsorbents on membrane fouling by natural organic matter. J. Membr. Sci. 310 2008. 356-364.

Lee, C., S. Bae, S. Han dan L. Kang. (2007). Application of Ultrafiltration Hybrid Membrane Process for Reuse of Secondary Efluent. Desalination. 202 2007. 239-246.

Lee, J., S. Vigneswaran, Y. Zhang, R. S. P. R. Reddy dan Z. Liu. (2017). Effective Natural Organic Matter Removal in Pond Water by Carbon Nanotube Membrane with Flocculation/Adsorption. Water Science \& Technology: Water Supply. 2017.

Malczewska, B. dan M. M. Benjamin. (2016). Efficacy og Hybrid Adsorption/Membrane Pretreatment for Low Pressure Membrane. Water Research. 99 2016. 263-271. 
Mozia, S. dan M. Tomaszewska. (2004). Treatment of Surface Water using Hybrid Process Adsorption on PAC and Ultrafiltration. Desalination. Vol. 162 2004. 23-31.

Mozia, S., M. Tomaszewska dan A. W. Morawski. (2005). Studies on the Effect of Humic Acids and Phenol on Adsorption-Ultrafiltration process performance. Water Research. Vol. 39 2005. 501-509.

Mahmud dan R. Noor. (2005). Kinetika Fouling Membran Ultrafiltrasi (UF) Pada Pengolahan Air Berwarna: Pengaruh Interval dan Lamanya Pencucian Balik (Backwashing) Membran. InfoTeknik. Vol. 6 No. 1 2005. (62-69).

Notodarmojo, S. dan A. Deniva. (2004). Penurunan Zat Organik dan Kekeruhan Menggunakan Teknologi Membran Ultrafiltrasi dengan Sistem Aliran Dead-End (Studi Kasus: Waduk Saguling, Padalarang). PROC> ITB Sains \& Tek. Vol. 36 A No. $12004.63-82$.

Syarfi, H. S. (2007). Rejeksi Zat Organik Air Gambut dengan Membran Ultrafiltrasi. Jurnal Sains dan Teknologi. Vol. 6 No. (1) 2007.

Tang, C., Z. He, F. Zhao, X. Liang dan Z. Li. (2014). Effects of cations on the formation of ultrafiltrasi membrane fouling layers when filtering fulvic acid. Desalination. 3522014. 174-180.

Wardani, A. K. (2013). Pengaruh Aditif pada Pembuatan Membran Ultrafiltrasi Berbasis Polisulfon untuk Pemurnian Air Gambut.

Zhang, M., C. Li, M. M. Benjamin dan Y. Chang. (2003). Fouling and Natural Organic Matter Removal in Adsorbent/Membrane Systems for Drinking Water Treatment. Environ. Sci. Technol. Vol. 37 No. 8 2003. 1663-1667.

Zularisam, A., A. Ismail, M. Salim, M. Sakinah dan H. Ozaki. (2007). The Effect of Natural Organic Matter (NOM) Fractions on Fouling Characteristics and Flux Recovery of Ultrafiltration Membranes. Desalination. Vol. 212 2007. 191-208.

Zularisam, A. W., A. F. Ismail dan R. Salim. (2006). Behaviours of Natural Organic Matter in Membrane Filtration for Surface Water Treatment-A Review. Desalination. Vol. 1942006. 211-231. 
JTAM Teknik Lingkungan Universitas Lambung Mangkurat, Vol 2 (2) Tahun 2019

Halaman ini sengaja dikosongkan 